\title{
The diffusion and influence of theoretical models of information behaviour. The case of Savolainen's ELIS model
}

González-Teruel, A. and Pérez-Pulido, M. (2020), "The diffusion and influence of theoretical models of information behaviour. The case of Savolainen's ELIS model", Journal of Documentation, Vol. 76 No. 5, pp. 1069-1089. https://doi.org/10.1108/JD-102019-0197

\section{Introduction}

According to Pettigrew and McKechnie (2001), the application of the theory in an area of research is a hallmark of its academic maturity and a requirement for delimiting it as a scientific discipline. For Fidel (2012) on the other hand, in addition to contributing to the development of a scientific field, the use of the theory in empirical research makes it easier to design, helps us to compare and interpret the results and paves the way to placing a study in a broader context. By following these guidelines, research on information behaviour (IB) has become an authentic test bed for various theories and theoretical models.

By the late twentieth century, McKechnie et al. (2001) were stating that in comparison with other areas of Library and Information Science (LIS), research on IB was a field with a highly developed theoretical basis. This theoretical background has continued into the early years of this century, with works of a theoretical character the most widely cited in specialist literature (González-Teruel et al., 2015). These reference points are theories that come from other social sciences and also theoretical models generated by the user's observation in specific environments. In both cases, the ontological, epistemological and methodological suppositions that inspired them are highly varied. Case and Given (2016) thus emphasise the difficulty arising from the abundance and diversity of these theories' philosophical presuppositions. This diversity prevents the formation of communities of discourse to discuss and compare the results of research into IB. In fact, specialist literature seems to have more interest in adopting or generating a new theory for studying a phenomenon than it does in the phenomenon itself, which in our case is the description, prediction or explanation of the user's IB. This is what makes it necessary to look back from a critical perspective when faced with a rich and abundant range of theoretical proposals, which may at times also be scattered and confusing. In order to do so, we have to track the diffusion and influence of the theories and theoretical models of IB, and analyse how they have been assimilated into the design of research contributing to the growth and consolidation of the field.

This was the approach taken by Vakkari (1998) when analysing the growth of a body of theoretical research based on a set of studies on the effects of task complexity on information source use. He took Wagner's and Berger's model of theory growth from sociology as a reference in this respect. The analysis presented the process of theoretical construction by showing its achievements, while also revealing gaps, contradictions and unanswered questions; a consideration of which might contribute to enriching this theory. On the same lines, but by way of a bibliographical review, Bawden (2006) analysed the effect of Wilson's 1981 article On user studies and information needs on the development of information science and, in particular, on the delimitation of the concepts of information, user studies and information needs. Urquhart (2011) adopted a similar bibliographical approach when investigating the theoretical research strategies commonly used in the study of IB, revealing that post-positivist or psychological and constructivist approaches were the most recurrent.

More recently, conceptual analysis inspired by Furner (2004) has led Savolainen (2016) to investigate the development of integrated models of IB and their contribution to conceptual growth in that field. He took Bunge's definition (1967) of the role of theoretical models as a reference for this purpose. Thus, for the seven models that he analysed, he determined that these had been generated by the juxtaposition of individual models, the cross-tabulating of components of various models, the linking of similar components from individual models or, finally, by incorporating components taken from various frameworks. On the other hand, he considered that such models had contributed to conceptual growth in the field of IB in three ways: by integrating parts of previously separate knowledge, by disseminating and explaining abstract knowledge and by expanding knowledge through the identification of new features of the object of study. Savolainen (2017a) went on to focus his research on the model of David Ellis (1989), revealing the way in which works whose point of reference was the model itself had contributed to conceptual growth. One of Savolainen's conclusions (2017a) was that despite the achievement that discussion of the above model 
supposed for progress in the construction of theory, research based on Ellis's model had not led to progress in the formulation or testing of hypotheses. As a result, they had not contributed to the transformation of this theoretical model into an empirically validated theory.

Bibliographical and conceptual research is accompanied by a series of outstanding works of a bibliometric nature, which analyse the dissemination of theories in LIS. The list includes research carried out by Cronin and Meho (2009), in which they analysed the citing in academic literature of a number of French theorists like Bourdieu, Derrida or Foucault; by Rosenbaum (2010), which focused on the dissemination of the ideas of Giddens; and McKechnie et al. (2012), investigating the use of postmodern approaches in IB research. The starting point of these works was an analysis of the direct cite (i.e. the number of times that a work expounding a theory is cited). They then went on to analyse such aspects as, for example, the evolution of the cite over a period of time or the thematic areas of the citing works. There is however a methodological approach which goes even further, by also engaging in an analysis of the context of the cite in the citing document, i.e. context citation analysis (CCA). For Zhang et al. (2013) and Ding et al. (2013), it is a method that can be used to operationalise and measure intangible concepts and connotations, as well as the intellectual process that the transfer and exchange of knowledge entail. It involves an analysis of the cites of a paper within the citing document. This research therefore does not just focus on the frequency of cites received, as is customary when assessing the impact of an investigation. CCA is based on the premise that not all cites are equal, and it analyses both these cites and the citing and/or cited documents from a syntactic and/or semantic point of view.

Bornmann and Daniel (2008) and Tahamtan and Bornmann (2019) have carried out an exhaustive review of studies that employ CCA. From the point of view of the dissemination of theories and theoretical models in LIS, works that stand out include McCain and Salvucci (2006), which focuses on analysing the diversity of concept symbols that The Mythical Man-Month by Frederick P. Brooks represented over years and across disciplines; Tsay's analysis (2009) of the work of Ted Nelson and the influence of the concept of hypertext on subsequent literature; Chang (2013), which investigates the influence on LIS of the key concepts contained in the article Question-negotiation and information seeking in libraries by Robert S. Taylor; or Chang (2016), which tackles the same objective by focusing on the book Human Behavior and the Principle of Least Effort, by George K. Zipf. More recently, Dewey (2016) has analysed cites in the context of the citing documents Archaeology of Knowledge and The Order of Things of Foucault in the literature on LIS, revealing a superficial use that diverges from the original text. Finally, González-Teruel and Abad Garcia (2018) have investigated the influence and degree of assimilation of the Information Poverty Theory (IPT), the Life in the Round Theory (LRT) and the Normative BehaviourTheory (NBT) of Elfreda Chatman.

The paper by González-Teruel and Abad Garcia (2018), included an analysis from the point of view of the citing documents and citations in the context of the documents concerned. The analysis of the citing documents revealed a greater number of IPT citations, followed by LRT and NBT. In addition, most the citing documents of the IPT and LRT were empirical, which presupposes the carrying-out of new observations that might validate or refute the theory. We likewise observed that citations of these theories in documents regarding areas other than LIS were around $17 \%$ for IPT, $10 \%$ for LRT, and insignificant for NBT. An analysis of citations in the context of citing documents nevertheless allowed for an in-depth examination of the diffusion and real influence of Chatman's theories in subsequent research, thereby revealing that more than half of the citing documents referring to any of the three theories included only a single quotation, which in turn points to a low relevance for the citing document as a whole. We likewise noted the small number of citations that appeared in the "theoretical framework" or "methods" sections, as well as the scant references to the core concepts of Chatman's theories. These results revealed a low rate of adoption of such theories, which are normally cited in a superficial way and without being incorporated into the design of the research. Neither the recognition of an author by the academic community (as in Chatman's case) nor the total number of times that his or her work is cited can therefore be considered an absolute indicator of its influence on subsequent research.

It is in this context that this work is being presented, following the approach initiated by González-Teruel and Abad Garcia (2018). Its objective has been to gauge the diffusion and influence of Savolainen's Everyday Life Information Seeking (ELIS) model, with particular reference to how it has been used as a theoretical and/or methodological basis of subsequent research. The ELIS model is, together with Chatman's theories, one of the most cited in IB research in the field of everyday life. Indeed, since its publication, the denomination "ELIS" has progressively been adopted as a shorthand term to identify 
studies and distinguish those focusing on IB in everyday life from those pertaining to a working environment (Savolainen, 2017b).

\section{Everyday Life Information Seeking model}

Reijo Savolainen published his ELIS model in 1995. Its development emerged from three basic concepts: way of life, mastery of life and everyday life information seeking (ELIS) (Fig. 1).

\section{EVERYDAY LIFE}

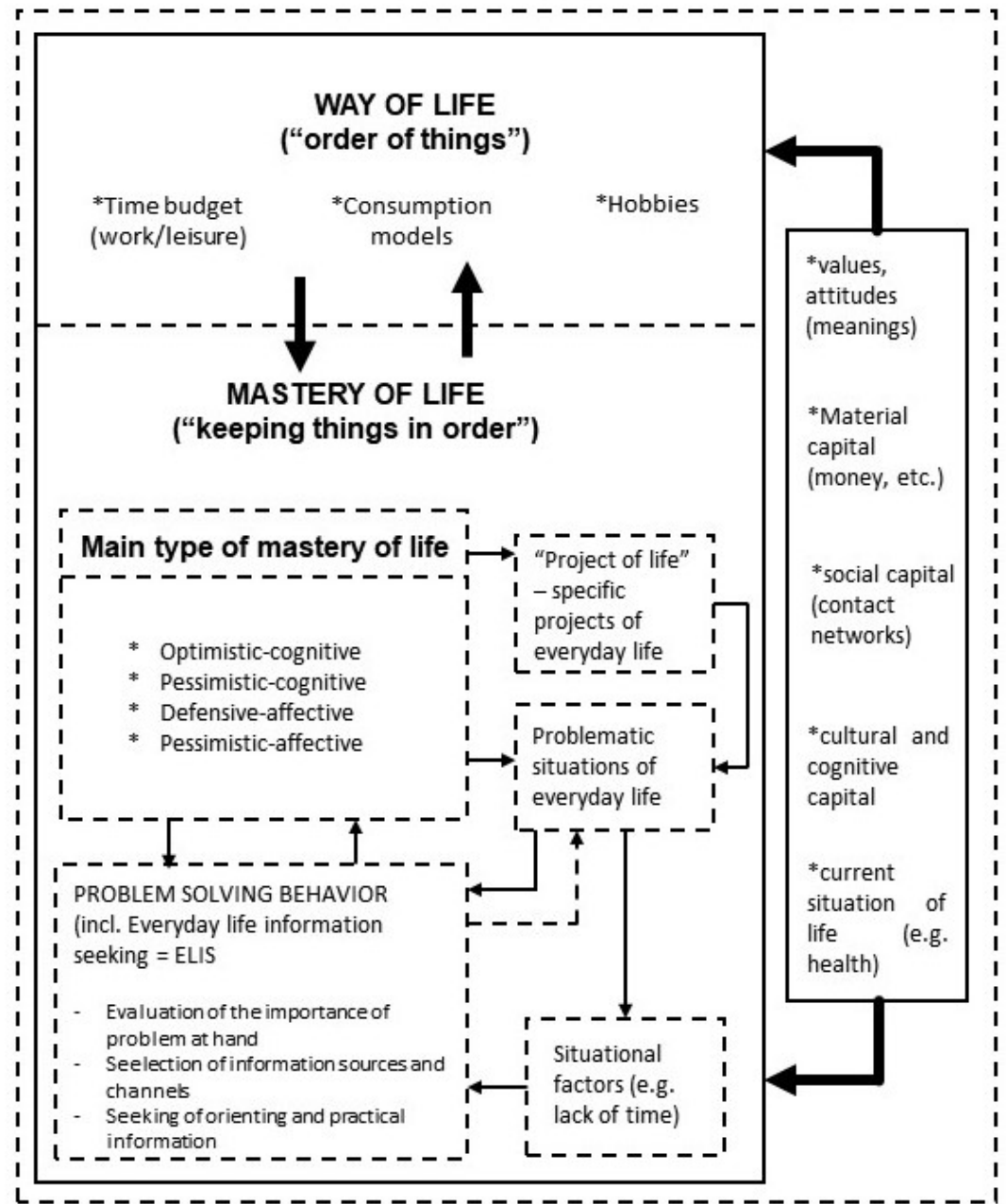

Fig 1. Everyday Life Information Seeking model (Savolainen, 1995, p.268)

Savolainen developed the first of these, the concept of "way of life", from Bourdieu's concept of habitus, understood as "... a socially and culturally determined system of thinking, perception, and evaluation, internalized by the individual ... a relatively stable system of dispositions by which individuals integrate their experiences and evaluate the importance of different choices." (Savolainen, 1995, pp. 261-262). He defines the concept of way of life in turn as the "order of things", based on the choices people make in their daily lives, such as - for example - the ways in which people prefer leisure activities or structure their time budgets. These "things" are the activities that take place in the area of life concerned (i.e. work, but also everyday activities like hobbies or housework), while the "order" refers to the preference assigned to such activities. This "order of things" is internalised by individuals (cognitive order) and determines what they consider "normal" or consistent with their everyday lives (Savolainen, 1995). Finally, "way of life" is conditioned by three factors: structure of time budget (the relationship between time devoted to work and 
free time), models of consumption of goods and services (expenditure on the acquisition of such items) and nature of hobbies (the nature of the things that people find most pleasant) (Savolainen, 1995).

The second concept of Savolainen's model is "mastery of life". As the "order of things" is not reproduced automatically, we need to use "mastery of life" to keep it going. This occurs passively when people are satisfied, since everything continues as expected (passive monitoring). It is active when we need to resolve a problem, and whenever we perceive the order of things as being threatened (active seeking of practically effective information). "Mastery of life" is therefore the characteristic or quality that allows us to deal with everyday problems. Savolainen believes that social class, and the culture and values involved in belonging to the social class concerned, determine how we deal with everyday problems, i.e. mastery of life. However, lived experiences also allow people to identify ways of dealing with problems. For this reason, previous experience - and the perceived usefulness of the sources and channels of information used to resolve everyday problems - affect information seeking habits by generating information for individual guidance. As a result, there are four types of mastery of life, based on two dimensions. There is on one hand the dimension that determines rationality applied to the resolution of problems, which is cognitive and affective. On the other, there is the dimension that describes expectations regarding the resolution of problems, which may be optimistic or pessimistic. Savolainen (1995, pp. 265-266) thus defines mastery of life is being optimistic-cognitive, pessimistic-cognitive, defensive-affective and pessimistic-affective.

The third concept is "everyday life information seeking" (ELIS), which Savolainen defines as "the acquisition of various informational (both cognitive and expressive) elements which people employ to orient themselves in daily life or to solve problems not directly connected with the performance of occupational tasks (Savolainen, 1995, pp. 266-267). Savolainen also recognises two dimensions of information seeking with regard to ELIS: seeking of orienting information without a specific objective, and seeking of practical information aimed at the resolution of a real and specific problem.

Finally, Savolainen (1995) explains his research framework on the basis of these three concepts. In this way, the way of life and the mastery of life are interrelated and mutually conditioned. Both aspects are affected by values and attitudes and current life situation, along with material, social and cultural/cognitive capital. The latter also have a special influence on the possibility of finding and using information. On the other hand, the two concepts alone cannot explain the way in which people seek information. "Way of life" provides only general criteria regarding the choice of sources and channels of information, i.e. the "order of things". At the same time, "mastery of life type" only reveals a person's tendency to adopt a certain search strategy; we also have to analyse other factors, such as the characteristics of the situation giving rise to the problem, the available sources and channels of information or the search for guidance or practical information.

\section{Research questions and method}

In order to comply with the proposed objective, this study addresses the following research questions:

- How has the citing of the ELIS model evolved? What types of research have adopted it as a reference, whether in LIS or in other areas?

- Has the ELIS model been an essential and relevant contribution to the citing works?

- Which aspects of the ELIS model have had the greatest impact on research that uses it as a theoretical reference?

To answer the above questions, context citation analysis (CCA) was carried out, guided by the proposals of Zhang et al. (2013) and Ding et al. (2013). It is, as already mentioned, a tried-and-tested methodology used to analyse the influence of the theories of Chatman (González-Teruel and Abad-Garcia, 2018), which allows us to obtain comparable results from two of the main theoretical developments in the field of everyday life information seeking.

\section{Cited and citing works}

The work initially cited as a reference for CCA was Savolainen's paper, published in 1995. It nevertheless emerged that many citing works cited a reduced version of the basics of this model, as described by Savolainen himself in 2005 in a chapter of a compendium of theories edited by Fisher, Erdelez and McKechnie and published in that year. For this reason, both works were considered to be cited works of 
reference, and likewise regarded as a unique bibliographical reference for analysing cites in the context of the citing documents concerned.

These citing works were retrieved from the Core Collection of the Web of Science (WoS) and Scopus in December 2018, without applying any publication date limit. 373 documents obtained from WoS and 436 from Scopus. The elimination of duplicate bibliographical records resulted in a list of 496 unique documents. Five of these were eliminated because they were in languages unknown to the authors (German, Farsi, Hungarian and Turkish). A further 15 books and 25 book chapters were excluded due to difficulties in obtaining such documents and analysing citations in the context of the work as a whole.

A complete search of the text of 451 documents was then carried out, resulting in the retrieval of 447 articles, conference proceedings and chapters of serials. The full text of four articles was not found due, respectively, to erroneous bibliographical information provided by the database (two documents), a conference presentation not yet published (one document) and non-availability (one document), even after attempts to contact the author both directly and via the interlibrary loan service of the authors' institution. Finally, and after a review of the 447 documents concerned, two more papers were eliminated due to their lack of any reference to Savolainen. A total of 445 citing documents were therefore analysed.

\section{Analysis of citing documents}

Analysis covered the year of publication, the type of work and the subject-matter of the citing documents concerned. The average annual number of cites was also obtained for the year publication.

The citing documents were classified by type, in accordance with the categories of the APA style manual (2010), as stated below:

- Empirical: Reports of original research that describe the systematic gathering and analysis of data for a particular purpose not considered or addressed in previous reports.

- Bibliographical: Bibliometric studies, content analysis, literature reviews, studies which analyse data obtained by others (secondary studies) or a bibliographical selection and comment of a specific aspect, in a systematic or narrative manner (or way).

- Theoretical: Literature-based studies that analyse the development of theories or concepts which delimit or expand theoretical constructs, or which present a new theory or model.

- Methodological: Studies that present new methodological approaches to the study of a problem (while introducing empirical data only for the purpose of illustrating the approach concerned).

- Other: Case studies, panels, editorials, etc.

Citing documents were classified as follows for the assigning of thematic categories:

- $\quad$ LIS document: if published in a periodical or series classified as "Information Science \& Library Science" by the Journal Citation Reports (JCR) or as "Library and Information Sciences" by the Scimago Journal \& Country Rank (SJCR).

- Non-LIS documents: documents not indexed as LIS by any of the above sources, in which case they were assigned one of the 27 major thematic categories of the SJCR.

\section{Theoretical incident or cite in citing document}

For the purposes of this research, a "theoretical incident" refers to a significant fragment of text in a citing document that specifically cites Savolainen $(1995,2005)$. After each citing document had been analysed, the cites regarding Savolainen's model $(1995,2005)$ or theoretical incident were extracted. The sentence in which the cite appeared was regarded as a unit of register, understood to be the unit of significance being analysed or the segment of minimum content (Bardin, 1986). Whenever the sentences before or after the cite referred to that cite, these were likewise included as a unit of context. The unit of context is the unit of understanding used for analysis of the unit of register or, in other words, the segment of the message whose size (greater than that of the unit of register) is ideal for grasping its precise significance (Bardin, 1986).

The unit of register and, where appropriate, the unit of context constituted the theoretical incident being analysed. These theoretical incidents were analysed for the frequency with which they appear in each citing document, for citing style and for cite location in citing works with an IMRaD (Introduction, Methods, 
Results and Discussion) structure, and content cited. The first step, to determine citing frequency, involved obtaining the number of theoretical incidents and the average of incidents per work. It was considered that "Those important references that make a major contribution to a given study appear in the text more frequently, while references providing only background information are mentioned just once in the text" (Hou et al. 2011, p. 724).

Secondly, four categories were established in order to determine the citation style. These were based on Bonzi (1982) and Zhang et al. (2013). In the view of these authors, “.... reference that is cited by an article, but is not obviously mentioned in the text, can be considered less relevant than one that is discussed in depth within the text of the citing article" (Zhang et al., 2013, p. 1498). Theoretical incidents were classified into the following categories:

a) Direct quotation:

ELIS is defined by Savolainen (1995) as "the acquisition of various informational (both cognitive and expressive) elements which people employ to orient themselves in daily life or to solve problems not directly connected with the performance of occupational tasks" (p. 267).

b) Specific, but interpreted, mention of a single work by Savolainen:

Firstly, the findings of Savolainen (1995) concerning the role of way-of-life in information seeking were used. In general, way-of-life can be defined as a meaningful order of everyday things; this order is determined by socioeconomic and cultural factors and ultimately, by the habitus of individuals.

c) Specific, but interpreted, mention of various works by Savolainen:

His socio-constructivist approach and the application of qualitative methods, including discourse analysis of people's perceptions about their competences as seekers and users of information, became an important contribution to our research (Savolainen 1999, 2002, 2004, 2005 and 2008).

d) Non-specific mention:

Information can also be acquired in a non-purposeful manner, through the passive monitoring of everyday life events in order to orient ourselves to our environments and keep our mental models of the world up to date (Bates 2002; McKenzie 2003; Savolainen 1995; Williamson 1998, 2005).

Thirdly, citation location was identified in the structured documents. This assumed that the section in which the theoretical incident appears is an important indication of the use that the author makes of the cited document and of the information contained in it (McCain and Turner, 1989). This was done by first establishing whether the theoretical incident appeared in the abstract, introduction, literature review, theoretical framework, methods, results, discussion or conclusion. The next step, after excluding the incidents that appeared in the abstract (in order to prevent the dispersion of results) was to group them according to whether they appeared in (a) the introduction or literature review $(\mathrm{I}+\mathrm{L})$, given that both sections describe the general context of the research concerned; (b) Theoretical Framework or Methods $(\mathrm{T}+\mathrm{M})$ detailing the design-related aspects of the research and/or (c) Results, Discussion or Conclusion $(\mathrm{R}+\mathrm{D}+\mathrm{C})$, which contextualise the results obtained from the research.

Finally, the contents of the theoretical incidents were analysed. This entailed first extracting the terms and expressions of Savolainen's $(1995,2005)$ ELIS model (e.g. way of life, time budget, consumption models, etc.) as well as others which, despite not forming part of this model, served as a basis for its development (e. g habitus). The second step was to create a master list to standardise the terms and expressions used in the reference work. The content cited in the theoretical incidents was then identified on the basis of this master list. With this identification complete, information was obtained on the frequency and percentage of incidents and on the documents in which they appeared. Furthermore, and in order to reveal the relationships between the concepts that appeared in the documents referred to above, a context co-citation analysis was performed. This assumed that "the frequency with which a given combination [of concepts] occurs in the sample of papers on the topic is a measure of the degree of consensus regarding the particular concept combination within the corpus"' (Small 1980, p. 183). The co-occurrences of terms were also 
extracted from the context of the documents concerned. A network of co-citation was then generated. Its nodes are the most significant terms obtained earlier, while its links represent the co-occurrences between terms. Bibexcel software was used to obtain the co-occurrences between the terms and networks of co-cites, and Gephi software was used to represent them graphically.

\section{Results}

\section{Citing documents}

Year of publication

Fig. 2 shows development over the year of publication of the documents citing Savolainen's ELIS model. It received its first two cites within two years of publication, and was cited 18.5 times per year on average during the period studied. The annual frequency of these citations has increased to date, albeit with fluctuations.

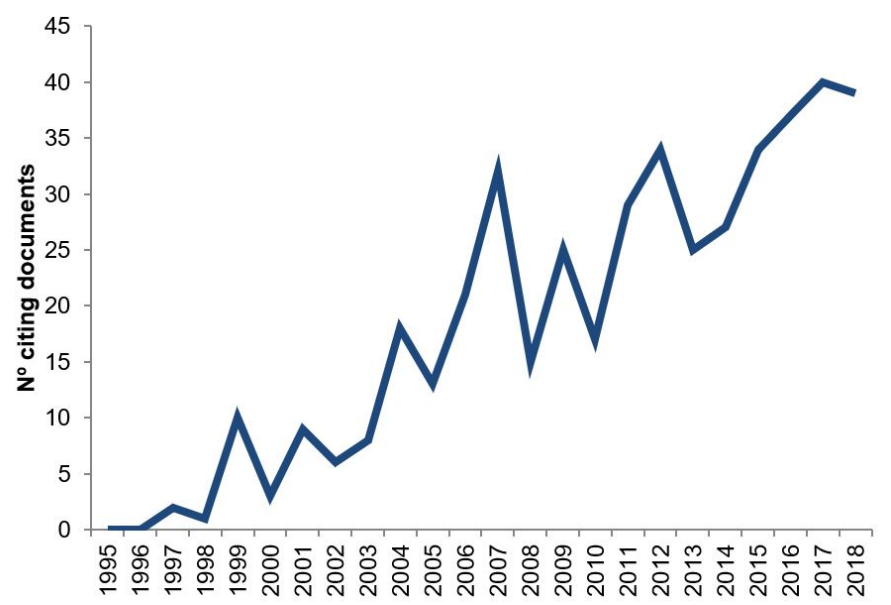

Fig. 2. Evolution of citing documents

\section{Type of work}

Most (68.3\%) of the citing documents were empirical, followed by bibliographical and theoretical works $(15.3 \%)$. A smaller number of citing documents $(1.8 \%)$ were works of methodology, or of other types (3.4\%). Fig. 3 shows evolution by type of citing document. It should be noted that empirical citing works are the most frequent throughout the period, with higher growth from the period 2001-2003. Bibliographical and theoretical works are the second- and third-most frequent. Despite their importance, they never exceed the totals of their empirical counterparts. The presence of methodological and other types of work is merely anecdotal throughout this period. 


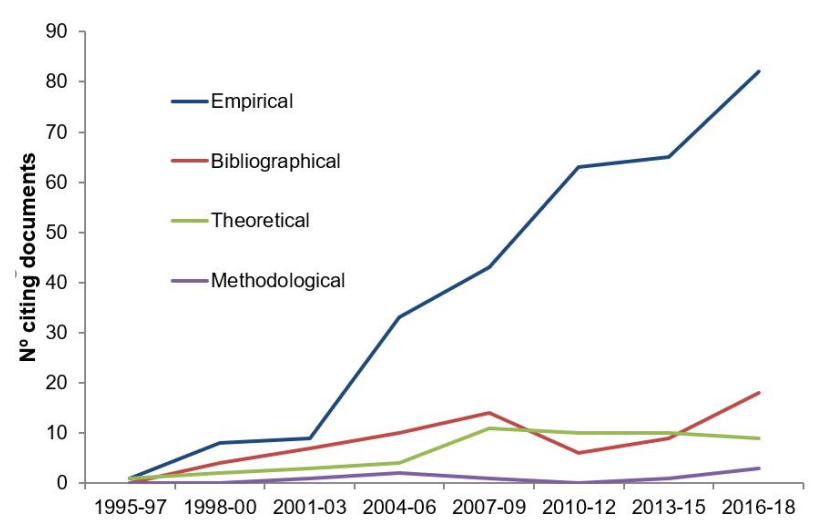

Fig. 3. Evolution of the type of citing document

\section{Subjects}

$20.2 \%$ of the document citing the ELIS model correspond to an area other than LIS (90 documents, of which 59 (65.6\%) are empirical). Fig. 4 shows the evolution of citing documents corresponding to areas other than LIS. Table 1 shows the areas to which citing documents considered to be non-LIS belong. Most of them correspond to Computer Sciences, followed by Social Sciences and Business Management and Accounting.

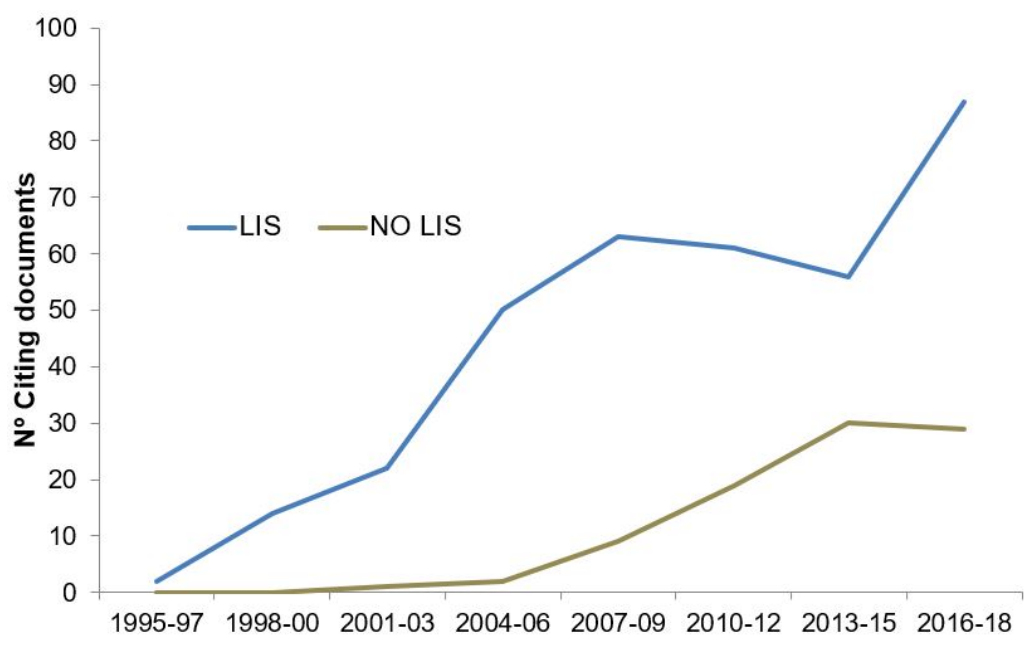

Fig. 4. Citing works in publications other than LIS

\begin{tabular}{|l|l|}
\hline Subject area & $\mathbf{\%}$ \\
\hline Computer Science & 72.2 \\
\hline Social Sciences & 22.2 \\
\hline Business, Management and Accounting & 20.0 \\
\hline Mathematics & 10,0 \\
\hline Medicine & 10.0 \\
\hline Engineering & 7.8 \\
\hline Psychology & 7.8 \\
\hline Arts and Humanities & 4.4 \\
\hline Economics, Econometrics and Finance & 3.3 \\
\hline Physics and Astronomy & 3.3 \\
\hline Environmental Science & 2.2 \\
\hline Nursing & 2.2 \\
\hline Agricultural and Biological Sciences & 1.1 \\
\hline Biochemistry, Genetics and Molecular Biology & 1.1 \\
\hline Earth and Planetary Sciences & 1.1 \\
\hline Education \& Educationa 1Research & 1.1 \\
\hline Energy & 1.1 \\
\hline
\end{tabular}




\section{\begin{tabular}{|l|l|}
\hline MaterialsScience & 1.1 \\
\hline
\end{tabular} \\ Table 1. Thematic areas, other than LIS, in which the citing works appeared}

\section{Theoretical incidents}

Analysis of the 445 citing documents revealed that five of them contained no citation in the actual text, but rather a bibliographical reference in the final list only. An analysis of cite frequency and style was therefore carried out on 440 citing documents, from which 811 theoretical incidents were obtained (Table 2). Furthermore, not all the citing documents had an IMRaD structure, so the analysis of the location of theoretical incidents refers to 302 documents with in-text citations that also have an IMRaD structure.

\begin{tabular}{|l|c|c|}
\hline & Analysed documents & Theoretical incidents \\
\hline Citing documents (CD) & 445 & \\
\hline CD with cite in text & 440 & 811 \\
\hline CD with cite in text and IMRaD structure & 302 & 557 \\
\hline
\end{tabular}

Table 2. Citing documents: citing documents with in-text citations, and citing documents with in-text citations and an IMRaD structure

\section{Frequency of citation}

There were 811 incidents in the 440 documents that cited the ELIS model in the text (an average of 1.8 incidents per document). A total of 284 documents (64.5\%) contained a single theoretical incident $(61.4 \%$ of LIS documents and $76.7 \%$ of non-LIS documents). Furthermore, of the whole set of documents, 138 (31.4\%) of them contained between two and five incidents $(33.7 \%$ of LIS documents; $22.2 \%$ of non-LIS documents), while 18 documents (4.1\%) contained six or more incidents ( $4.9 \%$ of LIS documents; $1.1 \%$ of non-LIS documents).

Given (2002), published in a journal classified as LIS, was, with 23 incidents, the document with the greatest number of theoretical incidents. This research takes the ELIS model as a reference framework for studying information behaviour in an academic context and that of the everyday lives of undergraduate students. On the other hand, the document regarded as non-LIS which contained most identified incidents was a paper published by Dörk et al. (2011, classified within the category Computer Science). This work describes the concept of "information flaneur" as a new human-centred view on information seeking based on an interdisciplinary point of view.

Finally, Fig. 5 shows how the figure for average incidents per document evolved throughout the period concerned. This remained fairly constant, fluctuating between 1.4 and 2 theoretical incidents per document over the period concerned, with the exception of the peak triggered by the above-mentioned paper by Given (2002), which raised the average to 3.2. Evolution in the case of documents classified as LIS coincides with what was observed for the total number of documents analysed (between 1.5 and 2.2 incidents per document), while in the case of non-LIS documents, the average number of incidents per document rises (from 0 to 1.3), coinciding with the increase in citations received by non-LIS publications (Fig. 4).

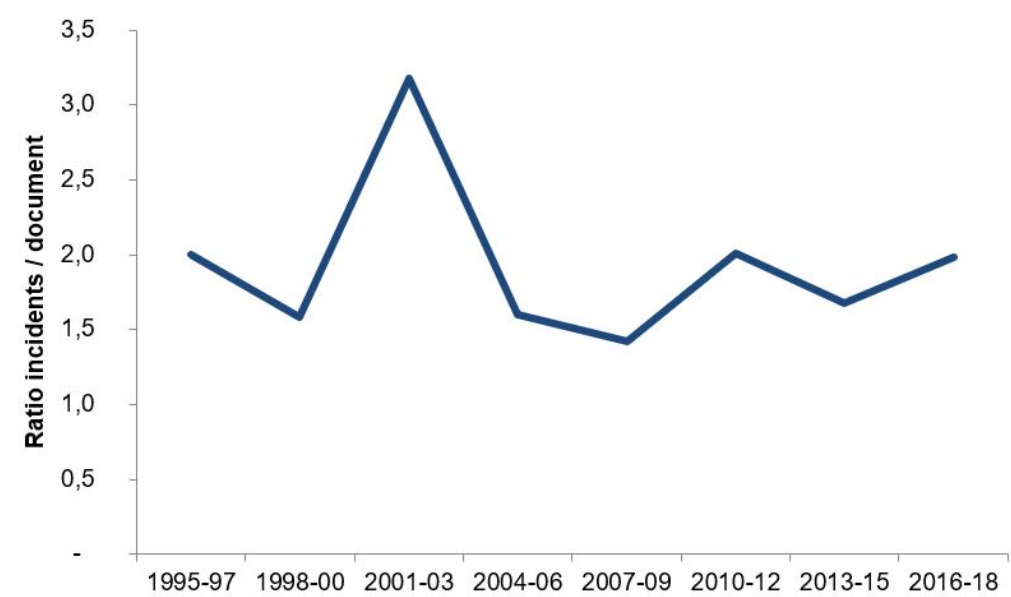

Fig. 5. Evolution of average incidents per document 


\section{Citation style}

The most frequent citation style was the specific (and interpreted) mention of a single work by Savolainen (Category B, 46.3\%), followed by the non-specific mention (Category D, 34.9\%), the direct cite (Category A, $13.7 \%$ ) and the specific (and interpreted) mention of several works by Savolainen (Category C, 5.1\%) (Table 3).

If we consider the cites classified in categories A and B as essential, given that they relate to a specific reference work, i.e. Savolainen $(1995,2005)$, and regard those of categories C and D as superficial or perfunctory, as they form part of sentences in which various works are cited, essential cites account for $60 \%$ of the total and superficial ones for $40 \%$.

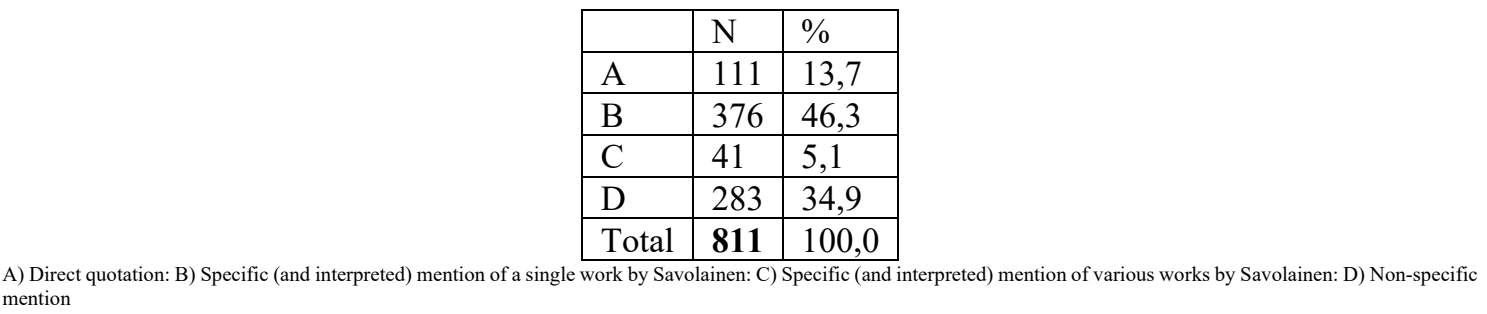

Table 3. Citation style

When we analyse the citation style of documents classified as LIS, the pattern is similar to that described for all documents, with $62.8 \%$ accounted for by essential cites and $37.2 \%$ by superficial ones. However, this pattern varies in the case of documents classed as non-LIS. In this case, the most common style is Category D, accounting for $51.6 \%$ of the incidents, followed by category B, with $39.7 \%$ of incidents. Essential cites account for $45.3 \%$ of the total, with $54.8 \%$ counting has superficial.

The evolution of the citation style did not reveal any clear pattern different to that of the global data. Incidents classed as Category D only exceeded those of Category B in the period 2007-2009.

\section{Citation location}

A total of 557 theoretical incidents (Table 2) were identified in the 302 documents with in-text citation and IMRaD structure. The headings with the greatest frequency were "Introduction" and "Literature review". These account between them for $60.9 \%$ of all incidents (Table 4). In second place, these theoretical incidents occurred under headings in which the results of research are contextualised ("Results", "Discussion" and "Conclusion"), accounting for $24.7 \%$ of citations. The headings under which these incidents least occur (13.7\% of citations) were those designed to present the design of the research ("Theoretical framework" and "Methods"). This pattern is repeated both in documents classified as LIS and in those classified as non-LIS.

\begin{tabular}{lrrrr|rl}
\hline & A & \multicolumn{1}{c}{ B } & \multicolumn{1}{c|}{ D } & \multicolumn{1}{l}{ N } & \% \\
\hline Abstract & & 4 & 1 & 5 & 0.9 \\
$\mathbf{I}+\mathbf{L}$ & 47 & 148 & 14 & 130 & 339 & 60.9 \\
\hline $\mathbf{T}+\mathbf{M}$ & 15 & 31 & 11 & 18 & 75 & 13.5 \\
\hline $\mathbf{R}+\mathbf{D}+\mathbf{C}$ & 17 & 75 & 7 & 39 & 138 & 24.8 \\
Total incidents & 79 & 258 & 32 & 188 & 557 & 100.0 \\
\hline
\end{tabular}

Table 4. Citation location and citation style

Table 4 also shows incidents by citation location and style of citation in documents with an IMRaD structure. The pattern that emerges here is the same as that corresponding to the set of IMRaD documents, where the most-frequent citation style under all headings is " $B$ ", followed by " $D$ ". On the other hand, the "A" and " $B$ " style (i.e. essential) incidents that occur in $\mathrm{T}+\mathrm{M}$ sections might be regarded as an indicator of a basic theory and/or explicit methodology. They account for a total of 46 incidents ( 8.3 of incidents in documents with an IMRaD structure).

Fig. 6 shows the evolution of the percentages of incidents corresponding to each of these three groups of headings. It can be seen that more than $50 \%$ of the incidents corresponding to this period belong to the 
introduction and literature review (I+L), with a figure of $100 \%$ for the initial years and up to $51.4 \%$ for later years. Incidents appearing under the headings of "Theoretical framework" and "Methodology" (T+M) accounted for $25 \%$ of the total in 1998-2000, albeit with fluctuation throughout the period, before accounting for fewer than $14.1 \%$ of all incidents by the end of it. Finally, incidents that appeared in the results, discussion and conclusions $(\mathrm{R}+\mathrm{D}+\mathrm{C})$ initially accounted for $21.4 \%$ of the total in 2001-2003, albeit with fluctuations, before attaining a figure of more than $34.5 \%$ by the end of this period. No difference was observed in this pattern when considering documents classed as LIS and non-LIS.

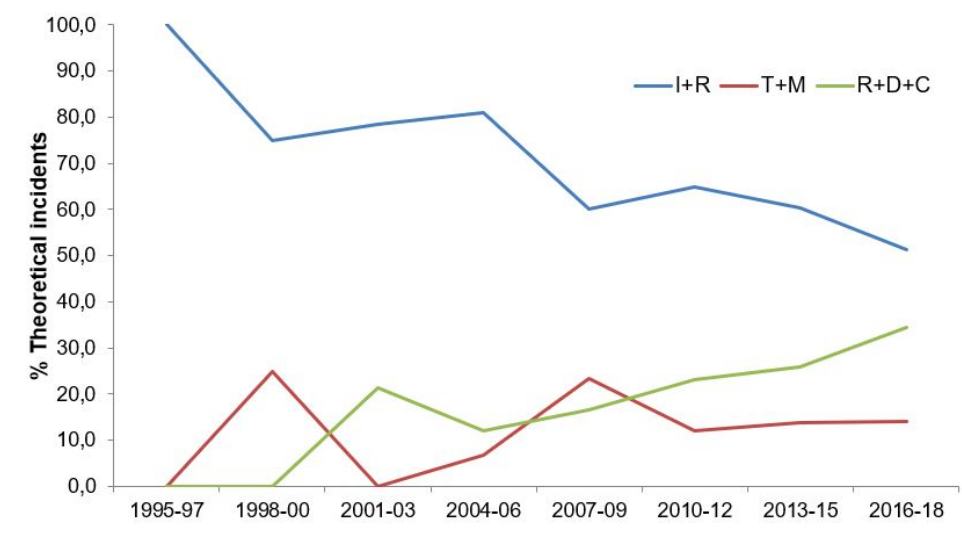

Fig.6. Citation location in citing documents

\section{Content cited}

Table 5 shows terms and expressions relating to the ELIS model that appear in at least $3 \%$ of the theoretical incidents obtained from the citing documents. A total of 511 theoretical incidents contain one or another of these items (63\% of incidents), in 303 different documents (68.9\% of the documents analysed). These figures are similar to those obtained for the LIS documents ( $64.7 \%$ of incidents in $70.7 \%$ of LIS documents). These figures are however lower for documents classified as non-LIS (54\% of incidents in 34.4\% of nonLIS documents).

\begin{tabular}{|l|r|r|r|r|}
\hline & \multicolumn{3}{|l|}{$\begin{array}{l}\text { Theoretical } \\
\text { incidents }\end{array}$} & \multicolumn{2}{|l|}{ Documents } \\
\hline & \multicolumn{1}{|c|}{$\mathbf{N}$} & \multicolumn{1}{c|}{$\%$} & \multicolumn{1}{c|}{$\mathbf{N}$} & $\mathbf{\%}$ \\
\hline EVERYDAY LIFE INFORMATION SEEKING & 282 & 34.8 & 209 & 47.5 \\
\hline MASTERY OF LIFE & 121 & 14.9 & 80 & 18.2 \\
\hline PROBLEM-SOLVING & 92 & 11.3 & 73 & 16.6 \\
\hline WAY OF LIFE & 97 & 12.0 & 68 & 15.5 \\
\hline HOBBIES & 32 & 3.9 & 30 & 6.8 \\
\hline COGNITIVE & 32 & 3.9 & 28 & 6.4 \\
\hline PRACTICAL INFORMATION & 30 & 3.7 & 27 & 6.1 \\
\hline ORDER OF THINGS & 28 & 3.5 & 26 & 5.9 \\
\hline VALUES/ATTITUDES & 32 & 3.9 & 26 & 5.9 \\
\hline AFFECTIVE & 29 & 3.6 & 25 & 5.7 \\
\hline ORIENTING INFORMATION & 34 & 4.2 & 25 & 5.7 \\
\hline HABITUS & 23 & 2.8 & 20 & 4.5 \\
\hline PASSIVE MONITORING & 20 & 2.5 & 18 & 4.1 \\
\hline SOCIAL CAPITAL & 24 & 3.0 & 17 & 3.9 \\
\hline
\end{tabular}

Table 5. Terms and expressions of the ELIS model which appear in the theoretical incidents analysed

As can be seen in Table 5, the concept that occurs most frequently is ELIS, accounting for 34.8\% of incidents in $47.5 \%$ of the documents analysed. It is important to note that in 158 incidents $(19.5 \%$ of the total) and 92 documents $(20.9 \%$ of total documents analysed), this was the only concept that appeared (Table 6). That is to say, only $43.5 \%$ of incidents and $48 \%$ of documents analysed contained various terms and expressions (in addition to the ELIS concept) referring to the theoretical model. Finally, and regardless of these figures, it is important to note that content explicitly related to the ELIS model is absent from 300 theoretical incidents (37\% of such incidents) in 137 analysed documents $(31.1 \%)$. 


\begin{tabular}{|l|c|c|c|c|}
\hline & \multicolumn{2}{|c|}{$\begin{array}{c}\text { Theoretical } \\
\text { incidents }\end{array}$} & \multicolumn{2}{c|}{ Documents } \\
\hline & $\mathbf{N}$ & $\mathbf{\%}$ & $\mathbf{N}$ & $\mathbf{\%}$ \\
\hline Other than ELIS concept & 229 & 28.2 & 94 & 21.4 \\
\hline ELIS concept + other & 124 & 15.3 & 117 & 26.6 \\
\hline Only ELIS concept & 158 & 19.5 & 92 & 20.9 \\
\hline No explicit content of the ELIS model & 300 & 37.0 & 137 & 31.1 \\
\hline Total & $\mathbf{8 1 1}$ & $\mathbf{1 0 0 . 0}$ & $\mathbf{4 4 0}$ & $\mathbf{1 0 0 . 0}$ \\
\hline
\end{tabular}

Table 6. Theoretical incidents and documents containing various terms and expressions; ELIS concept only, without any term.

The analysis of the co-occurrences between the most frequent terms in the documents analysed is shown in Fig. 7. Note there is a dense internal core connected to other terms and/or expressions. This corresponds to terms and expressions that appear together in a large number of documents, and also those associated with the majority of other terms and expressions. They are also the most-frequent mentions in Table 5: ELIS, problem-solving, mastery of life and way of life.

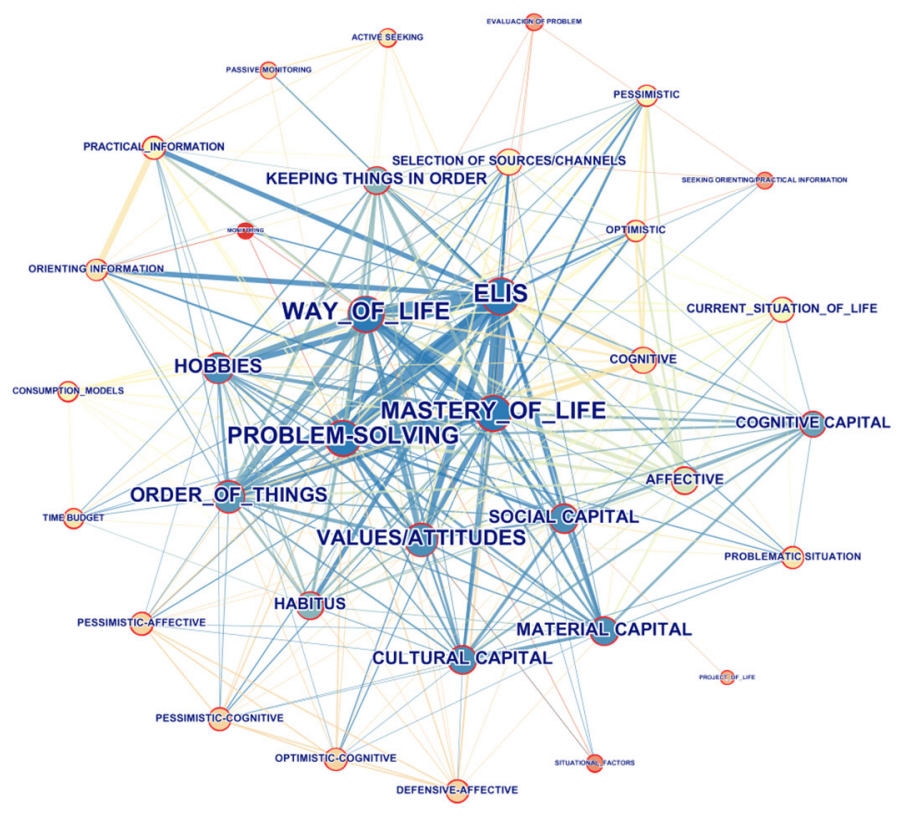

Fig. 7. Content cited (co-occurrences with a frequency greater than 2)

The most frequent co-occurrences of terms are therefore ELIS with problem-solving (55), with mastery of life (52) and way of life (46), mastery of life, along with way of life (41) and problem-solving (36). These are followed by co-occurrences of order of things and way of life (equivalent expressions) (24), affective and cognitive (23), mastery of life and order of things (23), ELIS and values/attitudes (23), ELIS and order of things (23), hobbies and way of life (22), orienting information and practical information (22), problemsolving and way of life (2) and ELIS and hobbies (20). The remaining co-occurrences have a frequency of less than 20 .

\section{Discussion}

Following the guidelines for the evaluation of scientific communication, citations of papers in which Savolainen presented his ELIS model are an indicator of their scientific impact. But the number of citations says very little about their contribution to the growth and consolidation of research in empirical, conceptual or theoretical terms. In this sense, this work offers a complementary vision, by introducing certain nuances that can be used to evaluate the aspects concerned. On the other, it uses a methodological design that has already been applied to Chatman's three theories (González-Teruel and Abad García, 2018), thereby also 
allowing us to compare the contributions made by two of the leading exponents of research into everyday life information seeking.

The results of this work offer a double perspective: that of the citing documents, and that of cites in the context of those citing documents. In this sense, the ELIS model received most cites in absolute terms, meaning that it has more impact than Chatman's Information Poverty Theory (IPT), which accounts for most citations of her three theories. The average number of citations per year (18.5 for the ELIS model, as opposed to 10.7 per year for the IPT) likewise corroborates this finding. We should however note the sudden interruption of Chatman's career in this respect, and the resulting end to her academic and scientific activity. Reijo Savolainen has nevertheless been developing this line of work over a long period, thereby gaining wide international recognition (Savolainen, 2017c). This might have given rise to the circumstances described by Milard and Tanguy (2018). These researchers claim that the recognition of an author's work in terms of cites cannot be assessed in isolation, but rather in relation to its social capital and, in the context of the social network of relationships, in relation to the community of researchers in the field concerned. We should also take into account the growth and weight of research into IB (Wilson, 2008; Hou et al., 2018) in the years since Chatman's death in 2002.

The figures relating to the number of empirical works that have cited the ELIS model likewise point to its greater significance over the theories of Chatman $(68.3 \%$ for the ELIS model, as opposed to $61 \%$ for the IPT). We should not forget that empirical research provides new observations of reality, which allow us to validate or refute initial concepts and propositions. On the other hand, a high percentage of empirical studies are in both cases consistent with Tuomaala et al. (2014) with regard to the increasing use, from 2005 onwards, of empirical strategies in research into LIS, which could also be interpreted, in the words of Cronin (2012), as "the quest to be seen as scientific".

Finally, and with regard to the significance of the ELIS model in areas other than LIS, the figures are higher than those obtained for any of the three theories of Chatman, with ELIS accounting for 20.2\% of citing documents, as opposed to $17.4 \%$ for the IPT. These also exceed the numbers obtained by Chang (2013) with respect to the work of Taylor, where the figure was $8.1 \%$. Nevertheless, the figure of $20.2 \%$ of citations for non-LIS publications obtained in the course of this present work is far removed from the figures offered by Wilson (2018) to show the influence of IB research outside LIS. This researcher has found that more than $50 \%$ of papers on IB are published in non-LIS journals. We should however take into account the fact that these figures have been obtained from sample articles containing the expressions "information behaviour", "information-seeking behaviour", "information-seeking" and "information needs", and not from an analysis of cites contained in articles published in LIS journals.

On the other hand, and in the same way as for the theories of Chatman, the largest number of non-LIS citations come from publications in the fields of Computer Science and Social Science (particularly the former, accounting for $72.2 \%$ of the non-LIS total). This result coincides with those obtained by Larivière et al. (2012) and by Cronin and Meho (2008), who show the progressive transformation of LIS into a discipline more likely to import citations than export them. These results nevertheless differ, once again, from those obtained by Wilson (2018). In this case, Health Sciences was the field with the highest incidence of own expressions referring to user-centred studies. The results regarding the quantity and areas of influence of research into IB therefore differ with the approach adopted in each case. We are inclined to think that the analysis of citations provides data closer to reality. In any case, the absolute figure obtained for number of documents or citations needs to be qualified through in-depth research. In the case of citations, an examination of such cites in context (see below) makes the influence of the ELIS model more relative in various ways, including its influence in fields other than LIS.

If we go down to the level of cites in the context of the citing documents concerned, our attention is drawn to the high number $(64.5 \%$ of the total) of citing works which include just one mention of Savolainen (1995, 2005). This coincides with the results obtained from the study of Chatman's theories (González-Teruel and Abad García, 2018). If this detail is striking in the context of the full set of citing documents, it is even more so when considering only documents considered to be non-LIS. In this case, the figure rises to $76.7 \%$ for documents containing unique theoretical incidents. The existence of unique citations in a citing document denotes a lack of relevance, to the citing document, of the cited reference concerned (Voos and Dagaev, 1976; Ding et al. 2013; Zhu et al. (2015). 2015). It is on the contrary possible to affirm that the greater the number of cites of a given work a citing document contains, the more relevant it is to that work. 
In fact, and as the results show, the document containing the largest number of theoretical incidents was that of Given (2016), which used the ELIS model for the design of its research.

The item that stands out with respect to style of citation is, as in the results obtained for Chatman's theories (González-Teruel and Abad García, 2018), the low percentage (just 13.7\%) of textual references to Savolainen's model. This detail could be interpreted as the existence of a high number of "ceremonial" citations (Rosenbaum, 2010) or a superficial use of the contents of the work being cited, as shown by Dewey (2016) in the case of references to Foucault in LIS. The results obtained nevertheless indicate a higher percentage of essential citations (of categories A and B) than those obtained for Chatman's IPT and LRT ( $60 \%$ for the ELIS model, compared to 54.6 and $49.6 \%$, respectively). However, in an analysis of the nonLIS documents alone, these percentages are once again lower, thereby making it possible to affirm that at least half of the citations corresponding to these documents are superficial. This detail, along with the high percentage of unique theoretical incidents, makes the importance of the ELIS model more relative for fields other than LIS.

With respect to citation location in a document, these results are consistent with work such as that of Boyack et al. (2018), which states that citations tend to be more concentrated at the beginning (introduction and literature review) and end of the text (discussion and conclusion), than under the headings in between, meaning that citations appearing outside the introductory sections of a text tend to have greater value. In comparison to the results obtained for Chatman's IPT, references to the ELIS model thus appeared more often in the initial sections of documents (60.9\%, as opposed to $48 \%)$, and to a lesser extent in the final sections (24.8\% compared to $32.7 \%)$ and in the central "theory and method" sections $(13.5 \%$ as opposed to $19 \%$ ). This indicates a greater use of the ELIS model as a resource for establishing the background of the research and, to a lesser extent, for contextualising the results. On the other hand, reference to the ELIS model for its incorporation into the design of research is scarce, both in comparison to the IPT and in absolute terms, in view of the few "essential" incidents (category A+B) that appeared under these headings, which could be considered as indicating scarce use of the ELIS model as a theoretical basis and/or explicit methodology. This fact is also revealed when comparing the evolution of citation style.

In this sense, if we compare the evolution of citation location in the ELIS model with the pattern established by Lu et al. (2017) regarding the existence of three successive phases in the citing cycle of a given work (discussion, reputation and adoption), the results indicate a low take-up of the theory. In first place, the data show an initial phase running up to 2006, which might clearly be identified as the "reputation" phase of Lu et al. (2017), in which more than $75 \%$ of incidents appeared in the introduction and literature review. There was, secondly, a short "adoption" phase in 2007-2009, in which a large percentage of incidents appeared under "Theoretical framework" and "Methodology", although this percentage dropped during the rest of the period, thereby giving relative importance to any possible adoption. Finally, there was a third phase (in 2010-2012), coinciding with an increase in the incidents appearing in the results, discussion or conclusion, to the detriment of those contained in the introduction and literature review. This would correspond to a phase prior to discussion, according to Lu et al. (2017). If this model is therefore taken as a reference, the influence of the ELIS model might be considered as being more in line with its reputation, given that it is one of the first theoretical models of IB and one of the few to focus on studying IB in non-work contexts (Savolainen, 2017b). However, discussion of the subject with respect to comparison and contextualisation of the results of research into LIS is recent, and it has not been widely adopted as a basis for designing research in this area. This pattern is identical to that obtained for Chatman's Information Poverty Theory (González-Teruel and Abad García, 2018).

Finally, when the presence of terms and expressions from the ELIS model in citations in context is analysed, two aspects are highlighted. The first of these is that one third of theoretical incidents and citing documents do not contain any specific term or expression referring to the ELIS model. The other is that in about $20 \%$ of incidents and documents, the ELIS concept is the only one that appears. These figures are even lower if we consider incidents contained in non-LIS documents only. Therefore, and for the set of incidents and documents as a whole, more than $50 \%$ of incidents and documents mention the ELIS model generically, without going into details. The interpretation here could be that whenever the ELIS concept appears frequently, it is mentioned as part of a specific line of IB research, thereby differentiating IB in a working environment from that of other areas of everyday life.

In the case of other incidents and documents in which various terms and expressions from the ELIS model appear, an analysis of co-occurrences allows them to be contextualised. For Small (1980), this type of 
analysis represents the structure of knowledge of the corpus of analysed texts, and identifies the ideas symbolised by the work cited, along with the degree of consensus between the articles and authors who cite it (Small, 1978). From this point of view, the results obtained for the ELIS model indicate a greater degree of consensus between citing documents than that obtained for Chatman's theories (González-Teruel and Abad García, 2018), represented by a greater number and higher concentration of co-occurrences among the terms concerned. These terms, among which greater consensus is observed, are the above-mentioned problem-solving, mastery of life and way of life of ELIS. However, this high degree of concentration in the co-citation network of these four expressions also indicates how other terms and expressions of the ELIS model, which need a better definition and operationalisation than that offered by the initial proposal of Savolainen (1995), are not being taken up by subsequent research (Dankasa, 2016).

In general terms, the method used in this research has allowed us to show how the diffusion and influence of the ELIS model, as previously occurred with the three theories of Chatman, are less than what is indicated by the total number of citations received in subsequent research. The interpretation of the results nevertheless needs to take into account two limitations. The first of these is that it would be possible to go further into the matter by, for example, looking at an author's reasons for citing an article, or examining the rhetorical function that the citation fulfils in the context of the document. Numerous previous articles have offered certain classifications that are more detailed and extensive than those used in this research, such as those reviewed by Zhang et al, (2013) and Tahamtan and Bornmann (2019). We have nevertheless opted for the categorisation previously used in Gonzalez-Teruel and Abad-Garcia (2018), as this permits comparisons between the diffusion and influence of Chatman's theories and the ELIS model of Savolainen. Future research will have to examine in greater depth the nature of the citations received by these theoretical references in the context of the citing documents concerned. The second limitation relates to the fact that CCA places the focus on the most immediate context of the cite (its phrase or paragraph), while isolating it from its more general context. This more-general context could be the entire document, other documents by the same author which likewise develop aspects of the document cited, taken as a reference; or even the author's social capital, which might partly explain the reasons for the citation. Apart from this, isolating citations and considering them only in their closest context has allowed us to transfer the research problem (in our case, the influence and impact of Savolainen's ELIS model) to a laboratory environment and learn about the nuances that lie behind the absolute number of citations. We also need to re-contextualise and evaluate the issue as a whole.

\section{Conclusion}

The results presented in this study refer to a theoretical model, which limits the possibility of making generalisations. It does however offer evidence about the superficial usage of theoretical references in research into LIS, as verified by authors such as Rosenbaum (2010) regarding the diffusion of the ideas of Giddens in LIS, McKechnie et al. (2012) for the use of postmodern approaches in IB research, Savolainen (2017a) for the Ellis model, Dewey (2016) regarding the proposals of Foucault and González-Teruel and Abad García (2018) for the theories of Chatman. The total number of citations received by Savolainen $(1995,2005)$ makes him one of the most important authors referred to in LIS research. But an in-depth analysis shows that incorporation into the design of subsequent research is scarce. One consequence of this is a limited construction of knowledge on the basis of what already exists, and a restricted supply of the new data needed to validate or refute initial theoretical propositions. As a result, we are still speaking, 25 years later, of the theoretical model of ELIS, and not the theory. The current problem with research into LIS or, more specifically, IB is not a lack of theory. There is no theoretical black hole (Brooks, 1989). What does exist is a style of research that tends to favour the following of an explicit theoretical line, rather than one likely to supply comparable new data. It is now necessary, more than ever, to recall the definition of the theoretical model of Marcia Bates (2005), in which proto-theories spend various years acting as beacons that guide research in the field, before a true theory can be formulated. But for this to happen, we need to review critically the contribution of research to the description, prediction and explanation of a phenomenon, while promoting a style of research that focuses on the same purpose.

\section{References}

APA. American Psychological Association. (2010), Publication Manual of the American Psychological Association, 6th ed., Washington, Washington.

Bardin, L. (1986), El Análisis de Contenido, Akal, Madrid. 
Bates, M.J. (2005), "An introduction to metatheories, theories, and models”, in Fisher, K.E., Erdelez, S. and McKechnie, L.E.F.F. (Eds.), Theories of Information Behavior, Information Today, Medford, pp. 124.

Bawden, D. (2006), “Users, user studies and human information behaviour", Journal of Documentation, Vol. 62 No. 6, pp. 671-679.

Bonzi, S. (1982), "Characteristics of a literature as predictors of relatedness between cited and citing works", Journal of the American Society for Information Science, Vol. 33 No. 4, pp. 208-216.

Bornmann, L. and Daniel, H. (2008), "What do citation counts measure? A review of studies on citing behavior", Journal of Documentation, Vol. 64 No. 1, pp. 45-80.

Boyack, K.W., van Eck, N.J., Colavizza, G. and Waltman, L. (2018), "Characterizing in-text citations in scientific articles: A large-scale analysis”, Journal of Informetrics, Vol. 12 No. 1, pp. 59-73.

Brooks, T.A. (1989), "The model of science and scientific models in librarianship", Library Trends, Vol. 38 No. 2, pp. 237-249.

Bunge, M. (1967), Scientific Research. Vol 1. The Search for System, Springer, Berlin.

Case, D.O. and Given, L.M. (2016), Looking for Information: A Survey of Research on Information Seeking, Needs, and Behavior, Emerald, Bingley.

Chang, Y.-W. (2013), “The influence of Taylor's paper, Question-Negotiation and Information-Seeking in Libraries", Information Processing \& Management, Vol. 49 No. 5, pp. 983-994.

Chang, Y.-W. (2016), "Influence of human behavior and the principle of least effort on library and information science research", Information Processing \& Management, Vol. 52 No. 4, pp. 658-669.

Cronin, B. (2012), "The waxing and waning of a field : reflections on information studies education", Information Research, Vol. 17 No. 3, p. paper 529.

Cronin, B. and Meho, L.I. (2008), "The shifting balance of intellectual trade in information studies", Journal of the American Society for Information Science and Technology, Vol. 59 No. 4, pp. 551-564.

Cronin, B. and Meho, L.I. (2009), "Receiving the French: a bibliometric snapshot of the impact of 'French theory' on information studies”, Journal of Information Science, Vol. 35 No. 4, pp. 398-413.

Dankasa, J. (2016), "Mapping the everyday life information needs of Catholic clergy", Journal of Documentation, Vol. 72 No. 3, pp. 549-568.

Dewey, S.H. (2016), “(Non-)use of Foucault's Archaeology of Knowledge and Order of Things in LIS journal literature, 1990-2015”, Journal of Documentation, Vol. 72 No. 3, pp. 454-489.

Ding, Y., Liu, X., Guo, C. and Cronin, B. (2013), "The distribution of references across texts: Some implications for citation analysis", Journal of Informetrics, Vol. 7 No. 3, pp. 583-592.

Dörk, M., Carpendale, S. and Williamson, C. (2011), "The information flaneur: A fresh look at information seeking", Proceedings of the 2011 Annual Conference on Human Factors in Computing Systems - CHI'11, ACM Press, New York, New York, USA, pp. 1215-1224.

Ellis, D. (1989), “A behavioural model for information retrieval system design”, Journal of Information Science, Vol. 15 No. 4-5, pp. 237-247.

Fidel, R. (2012), Human Information Interaction: An Ecological Approach to Information Behavior, MIT Press, Cambridge, Mass.

Fisher, K.E., Erdelez, S. and McKechnie, L.E.F. (Eds.) (2005), Theories of Information Behavior, Information Today, Medford.

Furner, J. (2004), "Conceptual analysis: A method for understanding information as evidence, and evidence as information”, Archival Science, Vol. 4 No. 3-4, pp. 233-265.

Given, L.M. (2002), “The academic and the everyday: Investigating the overlap in mature undergraduates' information-seeking behaviors", Library \& Information Science Research, Vol. 24 No. 1, pp. 17-29.

González-Teruel, A. and Abad-García, F. (2018), “The influence of Elfreda Chatman's theories: a citation context analysis", Scientometrics, Vol. 117 No. 3, pp. 1793-1819. 
González-Teruel, A., González-Alcaide, G., Barrios, M. and Abad-García, M.-F. (2015), "Mapping recent information behavior research: an analysis of co-authorship and co-citation networks", Scientometrics, Vol. 103 No. 2, pp. 687-705.

Hou, J., Yang, X. and Chen, C. (2018), "Emerging trends and new developments in information science: a document co-citation analysis (2009-2016)", Scientometrics, Vol. 115 No. 2, pp. 869-892.

Hou, W.-R., Li, M. and Niu, D.-K. (2011), "Counting citations in texts rather than reference lists to improve the accuracy of assessing scientific contribution”, BioEssays, Vol. 33 No. 10, pp. 724-727.

Larivière, V., Sugimoto, C.R. and Cronin, B. (2012), “A bibliometric chronicling of library and information science's first hundred years", Journal of the American Society for Information Science and Technology, Vol. 63 No. 5, pp. 997-1016.

Lu, C., Ding, Y. and Zhang, C. (2017), "Understanding the impact change of a highly cited article: a content-based citation analysis", Scientometrics, Vol. 112 No. 2, pp. 927-945.

McCain, K.W. and Salvucci, L.J. (2006), "How influential is Brooks' Law? A longitudinal citation context analysis of Frederick Brooks' The Mythical Man-Month”, Journal of Information Science, Vol. 32 No. 3 , pp. 277-295.

McKechnie, L.E.F., Pettigrew, K.E. and Joyce, S.L. (2001), "The origins and contextual use of theory in human information behaviour research", The New Review of Information Behaviour Research, Vol. 2 No. November, pp. 47-63.

McKechnie, L.E.F., Serantes, L.C. and Hoffman, C. (2012), "Dancing around the edges: the use of postmodern approaches in information behaviour research as evident in the published proceedings of the biennial ISIC conferences, 1996-2010", Information Research, Vol. 17 No 4, available at: http://InformationR.net/ir/17-4/paper548.html (accessed 31 October 2019).

Milard, B. and Tanguy, L. (2018), “Citations in scientific texts: do social relations matter?”, Journal of the Association for Information Science and Technology, Vol. 69 No. 11, pp. 1380-1395.

Pettigrew, K.E. and McKechnie, L. (E. F.. (2001), "The use of theory in information science research", Journal of the American Society for Information Science and Technology, Vol. 52 No. 1, pp. 62-73.

Rosenbaum, H. (2010), “Anthony Giddens’ Influence on Library and Information Science”, in Leckie, G.J., Given, L.M. and Buschman, J. (Eds.), Critical Theory for Library and Information Science, ABC-CLIO, Santa Barbara, CA, pp. 119-130.

Savolainen, R. (1995), "Everyday life information seeking: Approaching information seeking in the context of 'way of life"”, Library \& Information Science Research, Vol. 17 No. 3, pp. 259-294.

Savolainen, R. (2005), "Everyday life information seeking”, in Fisher, K.E., Erdelez, S. and McKechnie, L.E.F. (Eds.), Theories of Information Behavior, Information Today, Medford, pp. 143-148.

Savolainen, R. (2016), "Conceptual growth in integrated models for information behaviour", Journal of Documentation, Vol. 72 No. 4, pp. 648-673.

Savolainen, R. (2017a), “Contributions to conceptual growth: The elaboration of Ellis's model for information-seeking behavior", Journal of the Association for Information Science and Technology, Vol. 68 No. 3, pp. 594-608.

Savolainen, R. (2017b), “Everyday Life Information Seeking”, in McDonald, J.D. and Levine-Clark, M. (Eds.), Encyclopedia of Library and Information Science, 4th ed., CRC Press, Boca Raton, FL, pp. 15061515 .

Savolainen, R. (2017c), "Research in Information Science Award. Everyday Life Information Seeking", Bulletin of the Association for Information Science and Technology, Vol. 43 No. 3, pp. 53-56.

Small, H.G. (1978), “Cited documents as concept symbols”, Social Studies of Science, Vol. 8 No. 3, pp. $327-340$.

Small, H.G. (1980), "Co-citation context analysis and the structure of paradigms", Journal of Documentation, Vol. 36 No. 3, pp. 183-196. 
Tahamtan, I. and Bornmann, L. (2019), "What do citation counts measure? An updated review of studies on citations in scientific documents published between 2006 and 2018", available at: https://arxiv.org/abs/1906.04588 (accessed 31 October 2019).

Tsay, M.-Y. (2009), "Citation analysis of Ted Nelson's works and his influence on hypertext concept", Scientometrics, Vol. 79 No. 3, pp. 451-472.

Tuomaala, O., Järvelin, K. and Vakkari, P. (2014), "Evolution of library and information science, 19652005: Content analysis of journal articles", Journal of the Association for Information Science and Technology, Vol. 65 No. 7, pp. 1446-1462.

Urquhart, C.J. (2011), "Meta-synthesis of research on information seeking behaviour", Information Research, Vol. 16 No. 1, p. 7.

Vakkari, P. (1998), "Growth of theories on information seeking: An analysis of growth of a theoretical research program on the relation between task complexity and information seeking", Information Processing \& Management, Vol. 34 No. 2-3, pp. 361-382.

Voos, H. and Dagaev, K.S. (1976), “Are all citations equal? Or Did we op. cit. your idem?”, Journal of Academic Librarianship, Vol. 1, pp. 20-21.

Wilson, T. (2008), "The information user: past, present and future”, Journal of Information Science, Vol. 34 No. 4, pp. 457-464.

Wilson, T.D. (1981), “On user studies and information needs”, Journal of Documentation, Vol. 37 No. 1, pp. 3-15.

Wilson, T.D. (2018), “The diffusion of information behaviour research across disciplines", ISIC 2018 The Information Behaviour Conference. Kraków, Poland, 9-11 October 2018, Part 1. Information Research, Vol. 23 No 4, available at: http://www.informationr.net/ir/23-4/isic2018/isic1801.html (accessed 31 October 2019).

Zhang, G., Ding, Y. and Milojević, S. (2013), "Citation content analysis (CCA): A framework for syntactic and semantic analysis of citation content", Journal of the American Society for Information Science and Technology, Vol. 64 No. 7, pp. 1490-1503.

Zhu, X., Turney, P., Lemire, D. and Vellino, A. (2015), "Measuring academic influence: Not all citations are equal", Journal of the Association for Information Science and Technology, Vol. 66 No. 2, pp. 408427.

NOTE

[1] This refers to the ELIS concept, rather than the model. Generic allusion to the ELIS model in the incidents concerned has not been taken into account for this analysis. 